\section{Generalization gradients around a formerly positive $\mathrm{S}-*$}

\author{
THOMAS ZENTALL, University of Pittsburgh, Pittsburgh, Pa. 15213 \\ NORMAN COLLINS, Catholic University, Washington, D.C. 20017 \\ and \\ ELIOT HEARST, Indiana University, Bloomington, Ind. 47401
}

After mastering a successive discrimination between a blank key $\left(S^{+}\right)$and a vertical line ( $\mathrm{S}-$ ), two groups of pigeons were tested for line-tilt generalization in extinction. The vertical line had always been associated with nonreinforcement of keypecking in one group, but for the other group it had served earlier as a stimulus associated with reinforcement. All Ss in both groups yielded gradients with a minimum at the $\mathrm{S}-$ value, but the latter group made appreciably more responses during testing. Further generalization tests, conducted with reinforcement at all line-tilt values, suggested other differences between the groups.

The phenomenon of conditioned inhibition has recently regained popularity as a general subject for investigation in the field of animal learning (see the reviews of Konorski, 1967; Rescorla, 1969; and Hearst, Besley, \& Farthing, 1970). Operant research on this topic has usually involved the determination of generalization gradients around a stimulus (S-) that has been associated with nonreinforcement of an operant response, a procedure presumed to endow a stimulus with inhibitory properties. Gradients with a minimum at the $S-$ value along some dimension have typically been obtained in such studies.

In the present experiment we compared gradients of line-tilt generalization for two different types of $\mathrm{S}-$. Just before the generalization test, two groups of pigeons had mastered a discrimination between a blank white field (the stimulus associated with reinforcement, $S^{+}$) and a vertical black line on a white field (S-). However, the groups differed in the history of training given at $\mathrm{S}$-. The S- in one group had always been correlated with nonreinforcement of operant behavior, whereas the $S-$ in the other group had served earlier as an S+. Konorski (1967, Chap. VII)

* This study was supported in part by Grant Nos. MH-12120 (at the University of Missouri, Columbia) and $\mathrm{MH}-19300$ (at Indiana University) from the National Institute of Mental Health to the thi-f author, who also acknowledges the aid of the Institute of Human Learning. Berkeley, California, during the 1968-69 academic year. The work was carried out at the Department of Psychology, University of California, Berkeley. We appreciate the advice, equipment, and space generously provided by D. A Riley, who was supported by Grant No. MH-12485 from the National Institute of Mental Health. Reprints may be obtained from Thomas Zentall. Department of Psychology, University of Pittsburgh, Pittsburgh, $\mathrm{Pa}$. 15213. labeled the former type of stimulus a "primary inhibitory stimulus" and the latter a "secondary inhibitory stimulus," and he concluded that these different histories produced $S-S$ with noticeably different properties; for easier to convert into $\mathrm{S}+\mathrm{s}$ than are primary stimuli.

Unlike Konorski, who focused on measuring the effects of the presence vs absence of a specific $\mathrm{S}-$, we investigated the effects of varying some dimension of $S-$. Would the measurement of generalization around a previously positive $\mathrm{S}-$ yield gradients with a minimum at the $\mathrm{S}-$ value, as studies of a consistently negative $S-$ have generally revealed, or would the effects of prior reinforcement and extinction at $\mathrm{S}-$ interact to produce a flat gradient or value? Since these potential effects might depend on whether the generalization test was conducted within the context of uniform nonreinforcement at all dimensional values or uniform reinforcement at all values, we administered both kinds of test to every $S$.

SUBJECTS AND APPARATUS

Eight experimentally naive female (approximately 6 months old) were maintained at $75 \%$ of their ad lib feeding weights throughout the experiment. The response key in ar otherwise dark Lehigh Valley Electronics pigeon box was illuminated by stimuli projected from a miniature display unit. Seven different stimuli of approximately equal luminance were available: a white field (blank) or a white field bisected by a $1 / 8$-in.-wide black line of six possible orientations from the vertical $(0,+30,-30,+60,-60$, and $90 \mathrm{deg})$. Reinforcement was $3 \mathrm{sec}$ of access to mixed grain in the lighted magazine. example, secondary stimuli are much even one with a maximum at the $\mathrm{S}-$ White Carneaux pigeons
PROCEDURE

All Ss were run daily. On the first 4 days of the experiment, they were magazine trained, shaped to peck the key, and gradually shifted from a continuous reinforcement schedule to a 1-min variable interval (VI) schedule. For the four Ss randomly assigned to the "previously positive $\mathrm{S}-$ " group (positive to negative, to be labeled $P \rightarrow N$ ), the stimulus on the key was a 0-deg line. For the four Ss assigned to the "always negative S-" group (negative only, to be labeled N), the key was blank.

During the next 7 days, the $1-\min$ VI schedule was maintained. Birds received $60 \quad 30$-sec trials with either the 0-deg stimulus ( $P \rightarrow N$ Ss) or the blank key (N Ss). The intertrial interval (blackout) was $10 \mathrm{sec}$.

After the VI phase, all birds had to learn a successive discrimination between two possible stimuli on the key. For the $\mathrm{P} \rightarrow \mathrm{N}$ Ss, S+ was the 0-deg line, during which responding was reinforced on 1-min VI, and $\mathrm{S}-$ was the blank key, during which responding was extinguished. For the $\mathrm{N} \mathrm{Ss}, \mathrm{S}^{-}$was the blank key and $S-$ was the 0-deg line. Each 40-min daily session consisted of 30 presentations of $\mathrm{S}+$ and 30 presentations of $\mathrm{S}-$. Presentations of $\mathrm{S}+$ and $\mathrm{S}-$ lasted $30 \mathrm{sec}$, and they were separated by 10 -sec blackouts. Trials with the two stimuli occurred in a mixed order, under the constraint that neither stimulus could be presented on more than three consecutive trials. Each bird remained on its respective discrimination until the number of responses during $\mathrm{S}-$ was less than $10 \%$ of the total responses during both $\mathrm{S}+$ and $\mathrm{S}-$ throughout an entire session.

On the day after this criterion was met by a $\mathrm{P} \rightarrow \mathrm{N}$ bird, its $\mathrm{S}+$ and $\mathrm{S}-$ were reversed; $S+$ was now the blank key and $\mathrm{S}-$ the 0 -deg line. Reversal training was continued until the $10 \%$ criterion was again met.

A generalization test was given in extinction on the day after the criterial session of reversal learning for a $\mathrm{P} \rightarrow \mathrm{N} \mathrm{S}$ or of original learning for an $\mathrm{N}$ S. Note that the generalization test thus followed mastery of the same discrimination for all Ss.

A brief warmup of additional training, with VI reinforcement programmed during eight $\mathrm{S}+$ presentations and extinction during eight $S-$ presentations, preceded the generalization test. The test consisted of 12 randomized blocks of the seven stimuli (six line orientations and the blank) for a total of 84 presentations, each $30 \mathrm{sec}$ long and separated by 10 -sec blackouts. Four different 

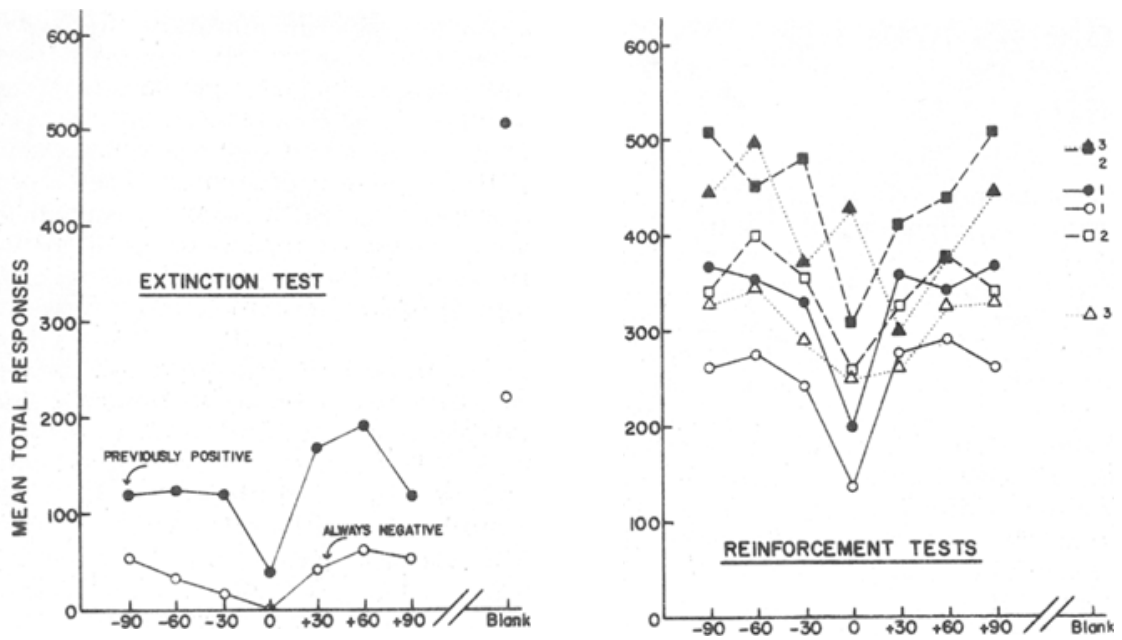

DEGREES OF TILT

Fig. 1. Gradients of absolute generalization for the extinction test and the three tests with reinforcement. Closed circles, squares, or triangles represent data for the $\mathbf{P} \rightarrow \mathbf{N}$ group and open circles, squares, or triangles, the $\mathbf{N}$ group. For both groups, the $S-$ during discrimination training just prior to the generalization test was a vertical line $(0 \mathrm{deg})$. The mean total responses to the blank stimulus $\left(\mathrm{S}^{+}\right)$are given on the extreme right of each panel.

sequences of the 84 stimuli were used, and each bird within a treatment received a different sequence. The number of responses during each 30-sec presentation was recorded.

On each of the 3 days after the test in extinction, all $S$ s received generalization tests with reinforcement available (resistance-to-reinforcement tests: Hearst et al, 1970). The number and duration of the stimulus presentations was the same as in the extinction test, but 1-min VI was in effect during all the different stimuli. No warmup trials were provided at the start of these sessions. A different sequence of stimulus presentations was used for each bird on each of the tests.

During the generalization test in extinction, we noticed that one bird in the $\mathrm{P} \rightarrow \mathrm{N}$ group had developed a bad limp, which persisted throughout the three tests with reinforcement. Its overall response rate, although ranking fifth highest out of the eight birds on the last day of training, was lower than any of the other seven birds during the extinction test. This bird's rate dwindled to less than 2.0 responses/min on the last day of testing with reinforcement, despite the fact that a 1-min VI schedule was in effect during all stimulus presentations. Because of the obvious physical disability of the bird and its marked loss of operant behavior, it will not be included in the analysis of results.

\section{RESULTS AND DISCUSSION}

The mean number of sessions to criterion on the original There was considerable overlap

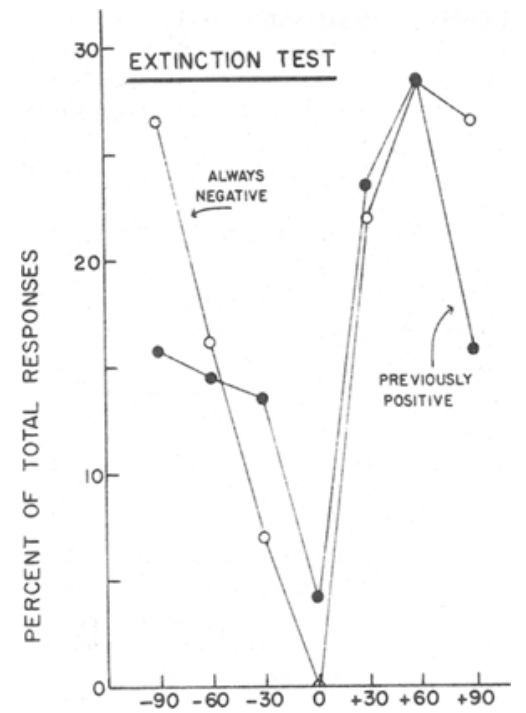

between the groups on these rate measures (for example, the fastest and slowest responders of the seven birds were both in the $\mathrm{N}$ group) and neither of the mean differences was significant $(\mathrm{F}<1)$.

The mean number of responses to each test stimulus is plotted in the absolute generalization gradients of Fig. 1, which includes results for the test in extinction (left panel) and for the three separate tests with reinforcement (right panel). For purposes of symmetry the same data point is plotted at both +90 and $-90 \mathrm{deg}$. Mean relative gradients, which equally weight $S$ s that differ in the absolute amount of generalization responding, are given for the extinction and reinforcement tests in Fig. 2.

During the test in extinction, both groups (and each of the seven individual birds) yielded gradients with a clear minimum at the $S-$ value. However, the two groups differed (Fig. 1) in the absolute number of responses given to the various test stimuli. For example, the $\mathbf{P} \rightarrow \mathrm{N}$ birds averaged 508.0 total responses to the six line tilts and the $\mathrm{N}$ birds, 223.3 responses, with no overlap between the scores of the two groups; similarly, responding to $\mathrm{S}^{+}$(blank) showed no between-group overlap. As far as the $\mathrm{S}-$ (vertical line) itself was concerned, the $\mathrm{P} \rightarrow \mathrm{N}$ Ss all responded to it and averaged $41.0 \mathrm{~S}-$ responses during the test, whereas none of the four $\mathrm{N}$ Ss made a single $\mathrm{S}-$ response. This result occurred even though just prior to the generalization test both groups had reached approximately the same low level of responding to $S-$.

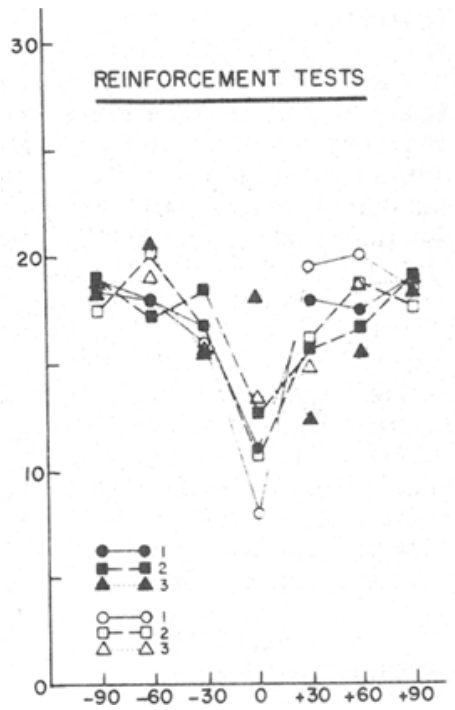

DEGREES OF TILT

Fig. 2. Gradients of relative generalization (mean percent of total responses to lines) for the extinction test and the three tests with reinforcement. 
Results from the tests with reinforcement, given on the right sides of Figs. 1 and 2, generally support the findings from the extinction test. Minima at the $S-$ value are characteristic of the group gradients for all 3 days of reinforcement in the $\mathrm{N}$ group, as well as of the group gradients for the first two tests in the $\mathbf{P} \rightarrow \mathbf{N}$ group. However, it is noteworthy that, of the three birds in the latter group, one showed more responding to the $\mathrm{S}-$ value than to any of the other line tilts (or blank) over the second and third test days, and another bird displayed this same effect on the third day. Although this outcome might be interpreted as revealing the previously positive function of $\mathrm{S}-$ (since none of the three $\mathrm{N}$ birds showed the effect on any day of testing), Hearst et al (1970) reported that continued testing with reinforcement at all dimensional values led often to a reversal of the original incremental gradient around an always-negative $\mathrm{S}-$; such gradient reversals generally appeared after 5-10 sessions of testing. Unfortunately, we gave only three reinforcement tests in the present experiment, so the opportunity to observe gradient reversals in our other Ss may have been lost.

In summary, the general shape of gradients around $\mathrm{S}-$ during tests in extinction was not greatly affected by prior training on a discrimination in which the final S- served as an S+. On the other hand, residual effects of the prior training were revealed in the sheer amount of test responding and possibly in the greater likelihood or rapidity with which one may observe gradient reversals when reinforcement is supplied at all dimensional values. These results appear to support Konorski's belief that "If a positive food CS is converted into a negative CS by nonreinforcement . . . the result of this conversion is unstable, and the previous positive character of the stimulus may be easily revealed... [Konorski, 1967, p. 323]." However, the interpretation and general applicability of our group differences would be greatly clarified by results from additional comparison groups, particularly ones in which (1) original reinforcement of responding at the previously positive $\mathrm{S}-$ does rot involve an $\mathrm{S}-$, or later extinction : $f$ responding at the $S-$ does not involve an $\mathrm{S}+$, or (2) the discrimination in the original learning phase is not the reverse of the final discrimination. Control groups of this kind would help to determine, for example, whether the obtained differences occurred because the $\mathrm{P} \rightarrow \mathrm{N}$ group had received more total reinforcements and sessions during training than the $\mathrm{N}$ group or because the $\mathrm{P} \rightarrow \mathrm{N}$ group had learned two discriminations before the generalization tests and the $\mathrm{N}$ group only one.

In conjunction with the generalization tests, it would be valuable in future work to determine whether the $\mathrm{S}-$ in the $\mathrm{P} \rightarrow \mathrm{N}$ birds would actually prove to be an "inhibitory stimulus" according to Rescorla's (1969) and Hearst et al's specific definitions and detection procedures, i.e., by combining $S-$ with a well-conditioned $\mathrm{S}+$ or by transforming $\mathrm{S}-$ into an $\mathrm{S}+$. Some recent work of Guth (personal communication, Indiana University, 1970) suggests that over a variety of experimental conditions a previously positive $\mathrm{S}-$ does not acquire inhibitory properties in rats; it will not reduce operant behavior when presented together with a strong $\mathrm{S}^{+}$, whereas a consistently negative $S$ will.

\section{REFERE NCES}

HEARST, E., BESLEY, S., \& FARTHING G. W. Inhibition and the stimulus control of operant behavior. Journal of the Experimental Analysis of Behavior, 1970 $14,373-409$.

KONORSKI, J. Integrative activity of the brain, Chicago, Ill: University of Chicago Press, 1967

RESCORLA, R. A. Pavlovian conditioned inhibition. Psychological Bulletin, 1969, 72, 77-94.

\title{
Effects of age and housing conditions on shock-induced aggression*
}

\author{
THOMAS L. CREER, CARIH, Denver, Colo. 80204 \\ and \\ D. A. POWELL, VA Hospital, Columbia, S.C. 29201
}

This study demonstrated that the stability of fighting rates over sessions was, in part, a function of how the Ss were housed outside the experimental chamber. Age was not shown to be an important determinant of elicited aggression, primarily because any effects of this variable were confounded by the variability produced by housing conditions.

Two variables shown to effect the rate of shock elicited aggression are housing conditions and age. Ulrich \& Azrin (1962), for example, reported that the same degree of fighting was induced by shock when rats were housed separately as when the same Ss were housed in pairs. However, a later study by Hutchinson, Ulrich, \& Azrin (1965) found that fighting in response to footshock occurred less frequently in rats housed separately than in rats housed in a colony. Age has also been shown to be a determinant of the rate of elicited aggression. Hutchinson et al (1965) reported that there was a direct relation between the rate of fighting and the $S$ 's age. While this finding was generally supported in a later study by Powell \& Creer (1969), they also suggested that the relationship between age and aggression was partially due to the confounding of age and the size of the enclosure in

* This research was supported by Public Health Service Research Grants MH 08775 and $M H 12025$ from the National Institute of Mental Health, R. W. Schaeffer, principal investigator. The study is based upon a section of the dissertation submitted by the senior author to Florida State University in partial fulfillment of the requirements for the PhD degree. The authors wish to express their sincere appreciation to Prof. $R$. W. Schaeffer for his support and encouragement during the course of this study. which the Ss were observed. Considering these few investigations, the tentative conclusion that can be drawn is that, while the frequency of induced aggression is a function of the age of the Ss and housing conditions, it is a complex relationship.

There were two purposes for conducting this experiment. The first purpose was to compare the rate of fighting that occurred over sessions between rats housed separately and rats housed two to a cage. Of particular interest was whether or not housing conditions had an effect on the number of sessions required for fighting to stabilize. The second purpose was to determine if there was a direct relation between the number of sessions needed for fighting to stabilize and age when Ss, housed separately or together, were paired in the test chamber for repeated sessions. APPARATUS

A Grason-Stadler Model E3125 rat box was used, in which the inner chamber measured $11 \frac{112}{2} 91 / 4$ $x 7-5 / 8$ in., with two sides constructed of metal and the other two of clear plastic. Shock from a Grason-Stadler No. 1064 GS shock source, equipped with a shock scrambler, was delivered to a grid floor which consisted of stainless steel rods, $3 / 32$ in. in diam and spaced $1 / 2$ in. apart. The door to the insulated test 